\title{
Preface
}

Welcome to the Journal of the Council for Research on Religion's special issue on Religion and Climate Change, distributed through the McGill University Library. This issue of JCREOR goes back to a colloquium held on September 20th, 2019, at McGill University, organized by the Montreal based Council for Research on Religion, in which several leading McGill scholars and an interested audience discussed the many intersections between religion and climate change. Special attention was given to the question of how Eastern and Western traditions, as well as traditions from ancient times, can inform us on how to better respond - socially, politically, ethically, spiritually - to the effects of present-day climate change. The colloquium took place while a crowd of 500,000 people in Montreal, inspired by the Swedish teenage activist Greta Thunberg, demonstrated against climate change.

Climate change involves not only catastrophic changes to the natural world in which we live, but also changes to our lives, our hopes and fears (increased anxiety, depression, doomsday feelings) as well as changes in society and politics (from new literary and film genres, to discussions about divesting, immigration politics, international relations etc.). Indeed, the present Covid-19 pandemic has clearly shown how everything and everyone in society is connected and intertwined, and that it is impossible to escape one's own responsibility. Let us all hope that the time for action has come now.

A special thanks goes to the participants of the Colloquium. First of all, co-organizer David K. Goodin, then presenters Lei Kuan Lai, Stephanie Posthumus, Darin Barney, Gregory Mikkelson, Claire Grenier. While some had already made other commitments and could not publish their papers with us, we have added contributions from David Aberbach, Federico Andreoni, Benjamin Keenan, Sean McGrath, and Aaron Ricker. We also want to thank the editors of this issue and of the EJournal, Amanda Rosini and Elyse MacLeod, as well as the team at McGill Library for their continued support and hard work.

Montreal, December 2020

Gerbern S. Oegema 
JCREOR Vol. 2, no. 1 (Fall/Winter 2020) iii

\section{Introduction to the Issue}

As we write this introduction, Montreal is under quarantine lock-down due to a global pandemic. It has shocked the world with a new reality. For most people, this kind of worldwide crisis had been thought to be the stuff of science fiction. Now it is daily life. Even leaving one's home is a life and death possibility. Yet mere months ago, so unimaginable was the threat of a pandemic that many considered it a hoax despite experts warning of its spread, even after the rising death reports started coming in. It led to an impasse on developing effective public policy initiatives to counter the pandemic. This situation is not unlike the current deadlock over the need for climate change mitigation policies. It too represents an existential threat to health, safety, and economic livelihoods around the world. We publish this collection of articles in the hope that the general public is finally ready to take seriously the reality of the global threat of climate change for our shared ecosphere.

The genesis for this special issue was a colloquium held on September 20th, 2019, at the McGill School of Religious Studies. The aim was to explore the intersections between religion, the humanities, and climate science, and how academic scholarship can inform public discourses and empower effective climate action. Invited speakers included Gerbern Oegema (McGill School of Religious Studies), David K. Goodin (McGill School of Religious Studies), Lei Kuan Rongdao Lai (McGill School of Religious Studies and Department of East Asian Studies), Stephanie Posthumus (McGill Department of Languages, Literatures, and Cultures), Darin Barney (McGill Department of Art History and Communication Studies), and Gregory Mikkelson (McGill School of Environment and Department of Philosophy). A number of contributions for this volume came from this event.

We also asked a student, Claire Grenier, to discuss her undergraduate research at this event, and invited student representatives of Divest McGill, Laura Mackey and Morgen Bertheussen, to present their case for collective action. We considered it especially important to include perspectives from the younger generation, and we purposefully scheduled this event one week ahead of a planned student "climate march" walkout. Divest McGill is an environmental justice campaign calling on McGill University to address the urgency of the climate crisis by withdrawing direct investments of its endowment fund from fossil fuel industries. It is a student-led organization that has, over the last seven years, committed time and energy into coordinating with other campus and community campaigns like McGill Faculty and Librarians for Divestment (MFL4D), Divest Concordia, Désinvestissons UdeM, Divest Mount-Allison, 350.org, and others. Collectively they represent part of a worldwide awakening to the dangers of climate change being led, for the most part, by students.

The urgency of climate change is underscored by the article that we have chosen to appear first. It is a piece written by Gregory Mikkelson that is revealing of the institutional realities facing the Divest Movement, and quite personal at the same time. He has made the decision to resign his positions with McGill University due to the administration's continuing refusal to divest from the fossil fuel industry. Entitled "Divestment and Democracy at a Canadian University," his article documents this history of institutional opposition as well as his rationale for taking this strong moral stand. All this, he writes, is given in the hope to inform and inspire others so that they can be better prepared in their own fight for institutional change:

The campaign to divest the endowment of McGill University from fossil fuel has had amazing success in using scientific knowledge to inspire democratic action. Organizations collectively representing all students and academic staff, and most non-academic staff, have voted overwhelmingly in favor of divest- 
JCREOR Vol. 2, no. 1 (Fall/Winter 2020) iv

ment. There is one small problem, however. Unlike Oxford or Cambridge, where a majority vote among all faculty would be the final word about any and all university policy, McGill suffers rule by a plutocratic Board of Governors. This impairment parallels and links to the stranglehold the fossil fuel industry has on Canadian environmental policy.

Our second article is by Benjamin Keenan and is entitled "Climate Change and Societal Response in the Maya Lowlands." The Shakespearean admonition that the past is prologue may be all too true when it comes to climate change. Keenan investigates how an ancient society tried to adapt to natural climate variation. It is a case study that reveals lessons for us today as we face global impacts from anthropogenic climate change:

This paper provides a summary of the scientific methods used in palaeoclimatology, the study of ancient climates, as well as an overview of the strategies employed by the Lowland Maya to adapt to natural climate change, and to tackle the issues associated with a growing population. The response of the Maya to these various challenges culminated in a societal restructuring, sometimes referred to as a collapse, in response to droughts between 800 and $1000 \mathrm{CE}$. The story of the Lowland Maya is particularly important to consider when confronting similar issues faced by twenty-first century society: feeding a growing population, water scarcity, disease occurrence, waste management, all in the context of anthropogenic climate change. These insights might lend useful perspective given that the effects of modern-day climate change are already being felt and will continue to be especially severe in tropical communities.

The next article is by David Auerbach, who examines how biblical narratives have shaped cultural self-understanding in his contribution, "Moral Issues, Literature and the Environment: from the Hebrew Bible to Modern Times." The exposé brings to light how people have struggled to define individuality and national identity during times of ecological stress and uncertainty:

Since the late eighteenth century, literature frequently follows the Bible in presenting environmental pollution and calamity in moral terms, as a consequence of human actions. Writers such as Blake, Wordsworth and Goethe are among the outspoken critics of wrong and immoral environmental policies and may be counted as early environmentalists, 'unacknowledged legislators of humanity,' as Shelley described poets at the end of A Defence of Poetry (1821). The proposed article focuses on environmental issues as reflected in two literary genres prominent from the time of the French Revolution until the early twentieth century: the genre of national poetry, which tends to stress the primacy of the Nation, usually in conflict with other nations or ethnic groups; and the genre of protest against the effects of industry, from the Industrial Revolution to the present.

These themes are further explored in an examination of the apocalyptical narratives that are increasingly used today to contextualize climate change. Gerbern Oegema investigates how biblical literature has come to be represented in popular discourses in his article "Climate Change as Apocalypse," and whether they can be properly described as apocalyptic:

This article wants to approach the discussion around climate change as a possible expression of an apocalyptic worldview. In order to do so, it will first give a brief history of research on apocalypticism and then see whether the discussion around climate change fits with the key aspects of an apocalyptic worldview.

These religious discourses become increasingly politicized in the public sphere, and nowhere has this dynamic become as prominent than in Evangelical Christian opposition to climate science. This socio- 
logical dynamic is examined in our next two articles, the first by Aaron Ricker, "Crisis, Conspiracy, and Community in Evangelical Climate Denial":

\begin{abstract}
Statistically speaking, American Evangelical Christians are uniquely attracted to apocalyptic conspiracy theories when it comes to the topic of climate change. Since Evangelicals constitute a powerful voting/lobbying/shopping bloc, it is worth asking why this might be the case and what (if anything) can be done about it. To this end, my study considers the relevance of two major cultural tributaries to American Evangelical pop apocalyptic culture. In the first section I consider biblical apocalyptic culture and argue that the characteristic apocalyptic promise to disclose hidden divine plans to a misunderstood but soon-to-be-vindicated elect group naturally entails conspiracy-theory thinking. I argue further that apocalyptic imagination and conspiracy-theory thinking are powerful tools for the definition of identity and community. In the second section I turn my attention to the kind of Evangelical pop apocalyptic culture that helped push climate science denial into the Christian mainstream. I argue that in pop apocalyptic productions like the influential tracts and comics of Jack T. Chick, the image of the elect as the persecuted and powerful bearers of special knowledge found a new lease on life, and continues to fascinate millions with the attractive offer of somebody special to be and somewhere special to belong. I conclude that apocalyptic questions of crisis and conspiracy have a sociological function, as means to the end of defining social identity. Understanding this concrete function of conspiracy-theory thinking in Christian apocalyptic imagination can help in assessing and addressing the troubling phenomenon of Evangelical climate denial.
\end{abstract}

Our next offering focuses this examination of the Evangelical Right by exploring the ideology and theology of this political movement. David Goodin takes as his case study the plight of environmental refugees and the politics that surround this politically charged issue in an article entitled, "Abrahamic Religions and Climate Change: Tradition and Political (In)action":

This article examines the theological worldview of the white Evangelical Protestant demographic group in terms of its political expression in the United States of America. Specifically, the politics over granting asylum to climate refugees is examined together with a critical overview of Abrahamic history on the care of strangers and the treatment of refugees. Also examined are related questions on the epistemological reality of climate change within the academic community. This research is brought together to assess the impact and influence of the white Evangelical Protestants on these controversies, and what can be done to counter the current political impasse that is blocking effective and meaningful climate change mitigation legislation and for granting asylum to climate refugees.

Diagnosis then moves to assessing the possibility of an eco-centric awakening within Christianity, which is discussed by Sean McGrath in his article, "Can the Earth Be Sacred Again? Christianity and Climate Change":

The following paper takes Pope Francis' Encyclical on Climate Change as an opportunity to re-open the debate, begun in 1967 by Lynn White Jr., on the theological origins of the environmental crisis. I note that the Pope's critique of consumerist modernity is strong, but his lack of a genealogical account of modernity remains a weakness of the text. I argue, with White, that the technological revolution which has caused climate change would not have been possible without Christian assumptions. The original disenchantment of the world was the Abrahamic revelation which disjoined divinity and nature, and contra to appearances, the disjunction was only exacerbated by the doctrine of the incarnation. With climate change, modernity is returning to this revelation in the form of the sobering experience of the precarity of the planet. Nature is now experienced as finite once again, and it includes us. Modernity, however, cannot be disavowed any more than disenchantment can easily be forgotten. A return to the 
JCREOR Vol. 2, no. 1 (Fall/Winter 2020) vi

Christian roots of disenchantment might help us to remember what we have forgotten: the virtue of contemplation, which could qualify modern attitudes of control and domination, and engender a Christian experience of reverence for nature. While this is Christian response to the climate crisis, other religious traditions will need to come to analogous forms of earth-centered ethics if we are to achieve the integrated ecological pluralism needed for the future of civilization.

The power of the human spirit to overcome the stark nihilism of climate inaction is revealed by Federico Andreoni in his article, "Music and Anthropogenic Climate Change: An Evolutionary Perspective." His essay shows how music can help create the social bonding and empathy needed to create the change we need:

This paper analyzes the role of music in raising awareness about anthropogenic climate change, that is, climate change generated by human activities, by investigating the biological, psychological, and social factors that underlie music's ability to generate empathy and social bonding among individuals. Empathy and social bonding are thought to be strong contributors in creating what evolutionary music theories (i.e. theories that focus on the evolutionary role of music) call social cohesion and group effort (i.e. the former being the synergy that drives members of a group to act for the benefit of the group as a whole, and the latter the effort played by the members of a group towards a common goal), both of which may be influential in the effort to raise awareness about and shape responses to climate change.

In June 2020, McGill University signed the Investing to Address Climate Change Charter (IACCC), a resolution that aims to address environmental sustainability with respect to endowment funds, which are used to generate revenue through investment. While the IACCC calls for limitations on McGill's investments, the document sets no concrete restrictions or timeframes. It is merely symbolic and only suggests that signatories measure the carbon intensity of investments, evaluate their progress, and commit to reducing fossil fuel investments over time. Could this be a first step toward meaningful action? Only time will tell. It will take sustained effort and diligence to ensure that this matter is not sidelined or forgotten. This volume serves that end as well. And perhaps more importantly, we hope to inspire our readers to pursue the social and ecological justice initiatives discussed herein, with all of us working together for a common future in our shared biosphere.

Montreal, December 2020

David K. Goodin

Gerbern S. Oegema 
